\title{
CLYPELLIANA MEJDALANII GEN.N. E SP.N. (HOMOPTERA, CICADELLIDAE, CICADELIINAE) DO MATO GROSSO E PARÁ, BRASIL ${ }^{1}$
}

\author{
Rodney Ramiro Cavichioli ${ }^{2}$
}

\begin{abstract}
ClyPELlIANA MEIDALANII GEN.N. AND SP.N. (HOMOPTERA, CiCADELlidAE, Cicadelinae) from MAto Grosso and PArí, Brasil. A new genus and new species are described from Mato Grosso and Pará, Brazil. Clypelliana gen.n. present clypellus strongly swollen, with two lateral lobes.

KEY WORDS. Homoptera, Cicadellide, Cicadellinae, Clypelliana mejdalanii, new genus and species
\end{abstract}

\section{Clypelliana gen.n.}

\section{Espécie-tipo: Clypelliana mejdalanii sp.n.}

Diagnose. Cabeça não pronunciada, com a margem anterior triangular e com carena na transição entre a coroa e a face; clípeo tão largo basalmente quanto longo, com as margens convergindo apicalmente; clipelo fortemente inflado basalmente, formando dois lobos laterais.

Descrição. Cabeça, em vista dorsal, não pronunciada, com comprimento mediano $1 / 4$ a 2/7 da distância transocular e $2 / 5$ a $3 / 7$ da interocular; margem anterior triangular, com carena na transição entre a coroa e a face; ocelos situados sobre a linha imaginária que tangencia os bordos anteriores dos olhos; superfície dorsal finamente pontuada; lóbulos supra-antenais, em vista dorsal, não proeminentes, lateralmente, levemente côncavos e ausente de carena; clípeo tão longo quanto sua largura basal, com as margens laterais levemente convergentes apicalmente, de perfil, pouco arqueado, com impressões musculares não tão nítidas; sutura transclipeal incompleta; clipelo fortemente inflado basalmente, formando dois lobos laterais, de perfil contínuo ao clípeo, sendo, o terço apical mais voltado para trás, margem apical convexa.

Pronoto tão largo quanto a cabeça, com comprimento mediano $4 / 7$ a 3/5 da largura entre os úmeros, margens laterais convergentes anteriormente e a posterior fortemente emarginada, superfície dorsal com muitas estrias transversas; carena notopleural completa.

1) Contribuição número 1006 do Departamento de Zoologia, Universidade Federal do Paraná.

2) Departamento de Zoologia, Universidade Federal do Paraná. Caixa Postal 19020, 81531-990 Curitiba, Paraná, Brasil. Bolsista do CNPq.

E-mail: cavich@bio.ufpr.br 
Escutelo tão largo basalmente quanto longo, sem estrias.

Tégminas quatro vezes mais longas do que largas, venação distinta e elevadas; com quatro células apicais, a quarta mais proximal do que a terceira; plexo e veias extranumerárias ausentes; com três células anteapicias fechadas. Asas quase tão longas quanto as tégminas e com $\mathrm{S}_{1+2}$ incompleta.

Pernas posteriores com a junção fêmur e tíbia não atingindo o proepímero; fórmula setal dos fêmures posteriores 2:1:0 (Holótipo), 2:0:0 e 2:1:1 (Parátipos); basitarsos posteriores igual a soma dos dois mais distais e superfície plantar com duas fileiras de microcerdas.

Pigóforo quase tão largo quanto longo, margem apical truncada, processos ausentes, com poucas macrocerdas distribuídas no terço apical inferior. Placa subgenital triangular, bipartida, abruptamente afilada no terço apical, atingindo $2 / 3$ do comprimento do pigóforo. Estilos curtos, truncados apicalmente, com lobos pré-apicais. Conetivo em forma de "T", com o talo alargado e carenado dorsalmente, ramos laterais bem divergentes, mais curtos do que o talo central. Edeago curto, de comprimento igual aos estilos, subcilíndrico, com ápice alargado e ausente de processos. Paráfise com a base em forma de barra, alargada medianamente e afilando-se para os lados, ramos articulados à base, delgados e afilados apicalmente.

Fêmea desconhecida.

Comentários. Clypelliana gen.n. apresenta carena na transição da coroa com a face e a junção fêmur-tíbia da perna posterior não atingindo o proepímero, características encontradas em Mesogonia Young, 1977 e Trichogonia Breddin, 1901. Porém, difere de Mesogonia pela robustez do corpo e caracteres da genitália. Relaciona-se com Trichogonia pelo aspecto da genitália, no entanto, apresenta parafíses bem desenvolvidas. Pelas características apresentadas na descrição, Clypelliana gen.n., inclui-se no grupo genérico Trichogonia criado por YOUNG (1977).

Etimologia. O nome do gênero é em função da característica do clipelo ser inflado basalmente.

\section{Clypelliana mejdalanii sp.n.}

Figs 1-9

Localidade-tipo: Holótipo Macho, com as seguintes etiquetas: BrasIL, Mato Grosso: $12^{\circ} 50^{\prime} \mathrm{S}-51^{\circ} 45^{\prime} \mathrm{W}$ [Ribeirão Cascalheira-MT], 2 machos, U[Itra].V[iolet]. Light T[rap]., B.E. Freeman [leg.], II-1968// Roy.Soc./Roy.Geog.Soc., Xavantina/Cachimbo. Expedition 1967-1969, B.M. 1970-192. Campo (The Natural History Museum, London).

Parátipos. Mesmos dados do holótipo, 2 machos, Dry Forest, (The Natural History Museum, London); 1 macho, Lake Hemmen, T. New 22.XI.1968// Grassland (The Natural History Museum, London); 1 macho, Gallery Forest// B.E. Freeman [leg.], 15.II-8.III.1968 (DZUP); 1 macho, Jacareacanga [Pará], Brasil, M alvarenga [leg.], XII.68 (DZUP); Sinop, Mato grosso, Brasil X-1975, M Alvarenga [leg.] (DZUP).

Descrição. Holótipo macho. Medidas (em mm): comprimento total: 9,20; comprimento mediano da cabeça: 0,72 ; distância transocular: 2,72 ; distância inte- 

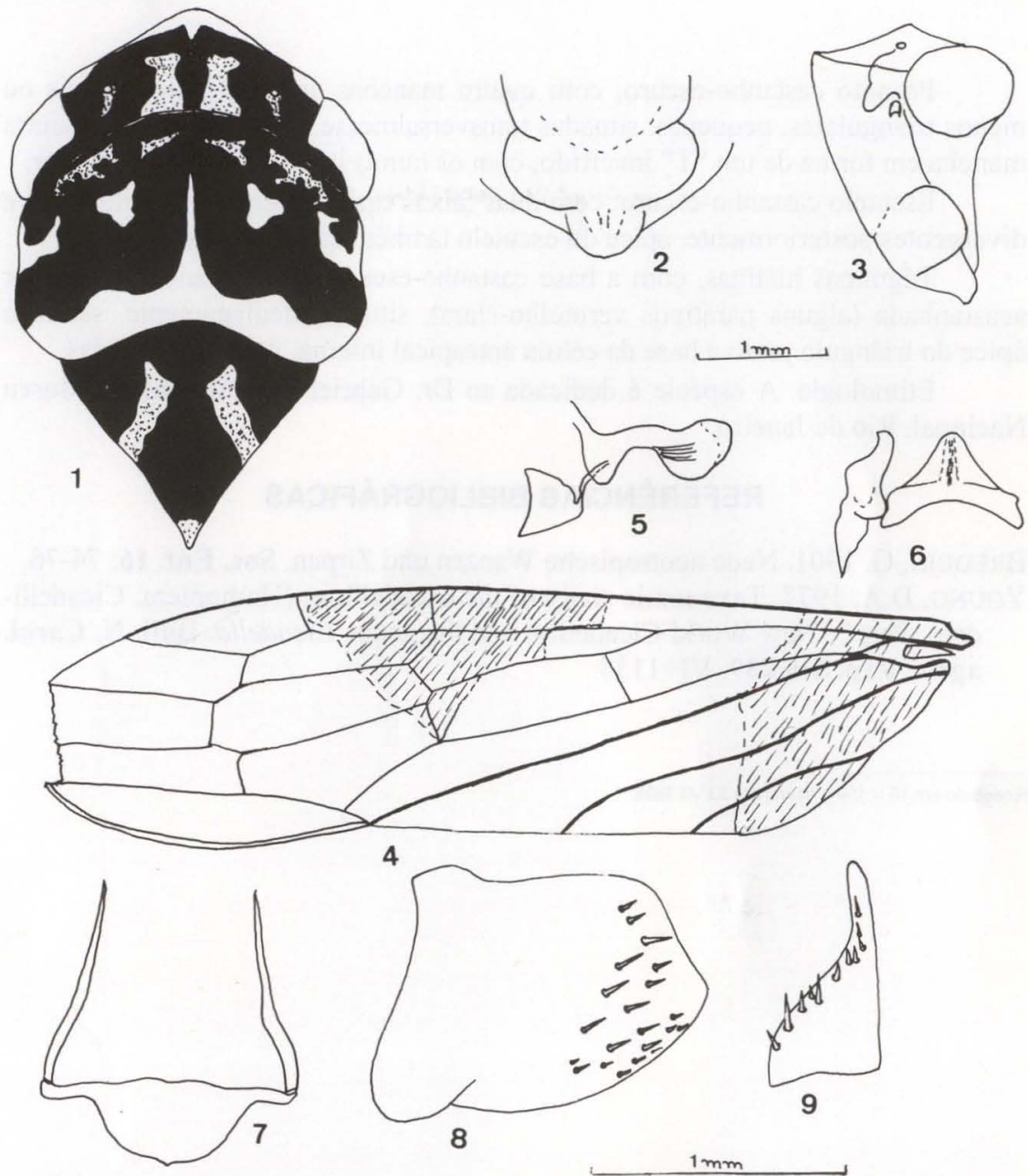

8

$1 \mathrm{~mm}$

Figs 1-9. (1-3) Holótipo: (1) cabeça, pronoto e escutelo, em vista dorsal; (2) cabeça, em vista lateral; (3) clipelo, em vista ventral; (4-8) parátipos: (4) tégmina esquerda; (5) edeago, em vista lateral; (6) connetivo e estilos, em vista dorsal; (7) paráfises, em vista dorsal; (8) pigóforo, em vista lateral; (9) placa subgenital, em vista ventral.

rocular: 1,72; comprimento mediano do pronoto: 1,72 ; distância entre os úmeros: 2,72; comprimento das tégminas: 7,20; largura máxima das tégminas: 1,68. Caracteres morfológicos e de genitália como na descrição do gênero.

Coloração. Coloração geral castanho-escura (alguns parátipos castanho-claro). Cabeça dorsalmente com uma faixa amarelo-pálida, estreita ao longo da margem anterior, com duas manchas castanho-clara, em forma de uma vírgula, opostas entre os ocelos e outras duas estreitas, também, castanho-claras, levemente curvadas para fora e sobre os ocelos, todo o restante do disco da coroa, castanho-escuro. Face inteiramente amarelo-pálida, exceto junto a carena, que se apresenta castanho-escura. 
Pronoto castanho-escuro, com quatro manchas amarelo-pálidas, mais ou menos triangulares, pequenas, situadas transversalmente na região mediana, outra mancha em forma de um " $T$ " invertido, com os ramos junto a margem posterior.

Escutelo castanho-escuro, com duas faixas castanho-claras, longitudinais e divergentes posteriormente, ápice do escutelo também castanho-claro.

Tégminas hialinas, com a base castanho-escura e uma mancha triangular acastanhada (alguns parátipos vermelho-clara), situada medianamente, sendo o ápice do triângulo junto a base da célula anteapical interna, veias escurecidas.

Etimologia. A espécie é dedicada ao Dr. Gabriel Luis Mejdalani, Museu Nacional, Rio de Janeiro.

\section{REFERÊNCIAS BIBLIOGRÁFICAS}

BREDDIN, G. 1901. Neue neotropische Wanzen und Zirpen. Soc. Ent. 16: 74-76. YounG, D.A. 1977. Taxonomic study of the Cicadellinae (Homoptera: Cicadellidae). Part 2. New World Cicadellini and the genus Cicadella. Bull. N. Carol. agric. Exp. Stn 239: VI+1135.

Recebido em 15.V.1997; aceito em 23.VII.1998 